\title{
DISTRIBUIÇÃO DO SISTEMA RADICULAR DA VIDEIRA EM VERTISSOLO SOB IRRIGAÇÃO LOCALIZADA
}

\author{
José Monteiro Soares ${ }^{1}$ e Tarcízio Nascimento ${ }^{2}$
}

\begin{abstract}
RESUMO
A distribuição do sistema radicular de videiras (Vitis vinifera L.) em um Vertissolo, em Juazeiro, BA, foi analisada em função do sistema de irrigação utilizado (microaspersão e gotejamento). Foram abertas trincheiras paralelas às linhas de plantas para amostragem de raízes por meio de monolitos; as plantas irrigadas por microaspersão apresentaram maior massa seca e melhor distribuição vertical de raízes até a profundidade de $120 \mathrm{~cm}$, em relação às videiras irrigadas por gotejamento que, por sua vez, mostraram concentração próxima aos emissores de água. A irrigação por microaspersão também condicionou melhor uniformidade de distribuição horizontal das raízes de videira, quando comparada com a irrigação por gotejamento.
\end{abstract}

Palavras-chave: Vitis vinifera, microaspersão, gotejamento, vertissolo

\section{ROOT DISTRIBUTION OF GRAPEVINE IN A VERTISOL UNDER LOCALIZED IRRIGATION}

\begin{abstract}
Root analysis of grapevine (Vitis vinifera L.) in a vertisol at Juazeiro-BA, Brazil $\left(9^{\circ} 22^{\prime} \mathrm{S} 40^{\circ} 26^{\prime} \mathrm{W}\right.$ ), was perfomed to verify the effect of the irrigation system used (microsprinkle and trickle) on root distribution. Trenchs parallel to the plant rows were dug to sample the roots by the monolite method. Microsprinkle irrigated plants showed greater dry matter and a better distribution up to $120 \mathrm{~cm}$ of depth compared to trickle irrigated plants, which showed a higher root concentration near emitters. The microsprinkle irrigation system also gave a better horizontal distribution of grapevine roots when compared to trickle irrigation.
\end{abstract}

Key words: Vitis vinifera, microsprinkle, trickle, vertisol

\section{INTRODUÇÃO}

A fruticultura é uma das principais atividades agrícolas da região do Submédio São Francisco, cuja área de cultivo da videira (Vitis vinifera L.) tem apresentado significativo aumento graças, em parte, às condições edafoclimáticas da região e à prática da irrigação. Desse modo, torna-se necessário o conhecimento das relações entre a água, o solo, a planta e a atmosfera, para a obtenção de produtividades economicamente rentáveis e de frutos que atendam às exigências dos mercados interno e externo. Nessas relações, é de grande importância a obtenção de informações referentes ao desenvolvimento e à distribuição do sistema radicular da videira, para o manejo adequado de água no solo, para se ajustarem o modo e a localização da aplicação de fertilizantes e para auxiliar na concepção de sistemas de irrigação.

Em regiões de clima temperado, o crescimento do sistema radicular da videira começa em torno de três semanas após a

\footnotetext{
${ }^{1}$ Eng. Agric. M. Sc. em Irrigação e Drenagem, EMBRAPA- Semi-Árido, CP 23, CEP 56300-000, Petrolina, PE. E-mail monteiro @ embrapa.cpatsa.br
} ${ }^{2}$ Eng. Agric. M. Sc. em Irrigação e Drenagem, EMBRAPA. Semi-Árido, CP 23, CEP 56.300-000, Petrolina, PE. E-mail tarcizio @ embrapa.cpatsa.br 
brotação das gemas, aumenta rapidamente, alcança o ponto máximo na fase de floração, declina de maneira acentuada até a fase de amolecimento da baga, quando então passa a aumentar novamente, atingindo então outro ponto de máxima, imediatamente após a maturação das bagas, para declinar em seguida (Kliewer, 1981). As raízes laterais apresentam-se uniformemente espaçadas e em pequeno número, ao longo de seu eixo, de onde proliferam, resultando numa concentração de raízes finas e pequenas, capazes de aumentar a capacidade de absorção de água e de nutrientes. Muitas raízes finas morrem algumas semanas após a sua emergência, mas são continuamente substituídas por outras que emergem desde que as condições do solo sejam favoráveis. Essa natureza efêmera das raízes finas e a troca do tecido do córtex das raízes permanentes contribuem para regular o teor de matéria orgânica usada na atividade microbiana. As videiras já desenvolvidas apresentam raízes estruturais lenhosas (de sustentação) cujas espessuras aumentaram através dos anos, com diâmetro variando entre 6 e $100 \mathrm{~mm}$. As raízes permanentes, com 2 a $6 \mathrm{~mm}$ de diâmetro, crescem horizontal e verticalmente, através do solo, dando origem a raízes mais finas e aos pelos absorventes (Richards, 1983).

A formação de novas raízes atinge o máximo no florescimento e no início do período de pós-colheita. Independente do regime de água do solo, o crescimento de novas raízes é muito pequeno nos períodos compreendidos entre a poda e a brotação e no período de desenvolvimento dos frutos e as raízes não suberizadas não se constituem no único caminho para o movimento de água do solo para a planta (Van Zyl, 1988).

A temperatura do solo, o suprimento de nutrientes e de água, a resistência mecânica, a aeração do solo e as interações entre esses fatores, influenciam o crescimento das raízes e suas funções, como sustentação da planta, armazenamento, absorção e translocação de reservas e o suprimento de substâncias de crescimento. A distribuição das raízes no perfil do solo é afetada pela densidade de plantio, pela frequência e profundidade do preparo do solo, pela utilização de cobertura morta e pelo sistema de irrigação, entre outros (Richards, 1983).

A classe de solo e os horizontes têm influência marcante na distribuição das raízes da videira, visto que solos com horizontes com boas propriedades físicas favorecem o desenvolvimento de um sistema radicular denso e profundo, mas decrescem gradativamente com a profundidade. Por outro lado, solos com horizontes com textura muito arenosa e baixo teor de matéria orgânica podem causar secamento muito rápido, com suprimento de água muito limitado, o que não permite um crescimento satisfatório das raízes. Solos com horizontes ácidos e alta densidade global também restringem o desenvolvimento radicular nas camadas mais profundas (Morlat \& Jacquet, 1993).

De acordo com Miller et al. (1975) frequentemente solos argilosos e solos pesados são usados como sinônimo, porém muitos solos pesados, com má drenagem e baixa permeabilidade, podem não ser da classe textural argilosa, porém um dos problemas mais importantes dos solos argilosos é o manejo de água, pois geralmente está acompanhado de baixa infiltração, baixa condutividade hidráulica e alta capacidade de retenção de água. Além desses atributos, os Vertissolos apresentam grande capacidade de expansão e/ou de se contraírem/fendilhar, sob processos de umedecimento e de secagem, respectivamente, o que depende da percentagem dos tipos e dos padrões de distribuição de argila no perfil.

A textura do solo também influencia na profundidade das raízes da videira. Solos com textura arenosa podem permitir uma distribuição radicular mais uniforme, através do seu perfil, em contraste com solos de textura moderadamente arenosa e argilosa, que favorecem a concentração das raízes nas primeiras camadas do solo (Nagarajah, 1987). A penetração da raiz da videira no perfil do solo diminui bruscamente para valores de densidade global maiores que $1,50 \mathrm{~g} / \mathrm{cm}^{3}$, mas sua influência também está correlacionada ao conteúdo de água, à distribuição do tamanho das partículas e ao espaço poroso que contém ar (Richards, 1983). A penetração da raiz também é influenciada pela porosidade (tamanho, rigidez e continuidade dos poros), considerada como um dos principais fatores que controlam a distribuição e o crescimento da raiz da videira (Seguin, 1972) uma vez que o principal mecanismo para a aeração do sistema radicular das plantas é feito pela difusão gasosa através da porosidade do solo (Taylor, 1949) ambos citados por Richards, (1983). Mesmo onde o conteúdo de água e a porosidade não são fatores limitantes, o crescimento da raiz pode, contudo, ser influenciado pela composição do ar em torno das raízes.

Os poros de solos úmidos são excessivamente preenchidos com água, o que bloqueia a passagem ou a difusão dos gases através do seu perfil. Sides \& Barden (1970) citados por Miller et al. (1975) concluíram que a difusão do ar através da água, em solos argilosos saturados, é muito baixa, por causa das constrições dos poros e do aumento da viscosidade da água nos poros, quando a superfície das partículas sólidas comprime as paredes dos poros, devido ao movimento expansivo das partículas de argila.

Os sistemas de irrigação também podem afetar a distribuição das raízes no solo. Segundo Van Zyl (1988) a distribuição horizontal do sistema radicular da videira foi mais uniforme sob irrigação por microaspersão que sob gotejamento. Embora o número total das raízes tenha sido o mesmo para ambos os sistemas de irrigação, $65 \%$ das raízes concentraram-se dentro de um raio de $50 \mathrm{~cm}$ em relação ao gotejador, mas decresceram rapidamente no sentido transversal à fileira de plantas. Este padrão de distribuição de raízes estava por demais relacionado com o padrão de molhamento dos emissores, cujo diâmetro do bulbo úmido era de $1,00 \mathrm{~m}$. Na região semi-árida do Nordeste, para culturas de pequeno espaçamento como a videira, os sistemas de irrigação por gotejamento e por microaspersão têm sido projetados de maneira a formar uma faixa úmida contínua, ao longo da fileira de plantas.

De acordo com Richards (1983) a distribuição do sistema radicular da videira sob irrigação por gotejamento depende do tipo de solo, do volume de solo molhado, da quantidade de água aplicada, da frequência de irrigação e do espaçamento entre emissores. Em solos argilosos com densidade global em torno de $1,50 \mathrm{~g} / \mathrm{cm}^{3}$, a irrigação por gotejamento proporcionou padrões de umedecimento do solo similares ao formato de uma cebola, o que resultou na formação de zonas secas livres de raízes na camada superficial do solo, entre os emissores, e restringiu o desenvolvimento do sistema radicular em profundidade (Richards, 1983).

Dentre os vários meios para a investigação de sistemas radiculares, Schuurman \& Goedewaagen (1965) afirmam que o método do monolito fornece uma amostra completa da estrutura, da forma e do número total das raízes, além de permitir, também, uma visualização da distribuição do sistema radicular, ao longo do perfil do solo, inclusive máxima profundidade alcançada.

A análise do comportamento do sistema radicular das culturas possibilita melhor compreensão das relações solo-águaplanta-atmosfera, que são de fundamental importância para a prática da agricultura irrigada; assim, este trabalho objetivou analisar a distribuição do sistema radicular de videira, sob irrigação localizada, na região do Submédio São Francisco. 


\section{MATERIAL E MÉTODOS}

O estudo foi realizado no Campo Experimental de Mandacaru, pertencente ao Centro de Pesquisa Agropecuária do Trópico Semi-Árido (EMBRAPA-CPATSA), situado no Projeto de Irrigação de Mandacaru, Juazeiro, BA, num solo da classe Vertissolo. Utilizou-se um pomar de videira variedade Itália, com quatorze anos de idade e espaçada em $3 \mathrm{~m} \times 2 \mathrm{~m}$, sendo parte irrigada por microaspersão, utilizando-se um emissor por planta com vazão de $70 \ell \cdot \mathrm{h}^{-1}$, e parte irrigada por gotejamento, usando-se emissores com vazão de $4 \ell . h^{-1}$ espaçados de $1 \mathrm{~m}$, sendo diária a frequência de irrigação de ambos. A determinação da granulometria e da argila natural foi feita pelo método da pipeta e a densidade global pelo método do anel volumétrico (EMBRAPA, 1979). Os resultados dessas análises físicas constam da Tabela 1.

Tabela 1. Características físicas do Vertissolo do Campo Experimental Mandacaru Área III, Juazeiro, BA, 1995

\begin{tabular}{cccccc}
\hline $\begin{array}{c}\text { Profundidade } \\
(\mathrm{cm})\end{array}$ & Areia & Silte & $\begin{array}{c}\text { Argila } \\
\mathrm{g} \cdot \mathrm{kg}^{-1}\end{array}$ & $\begin{array}{c}\text { Argila } \\
\text { natural }\end{array}$ & $\begin{array}{c}\text { Densidade } \\
\text { global } \\
\text { g.cm }\end{array}$ \\
\hline $0-30$ & 170 & 240 & 590 & 490 & 1,52 \\
$30-60$ & 150 & 270 & 580 & 450 & 1,55 \\
$60-90$ & 130 & 240 & 630 & 520 & 1,54 \\
$90-120$ & 130 & 270 & 600 & 500 & 1,54 \\
\hline
\end{tabular}

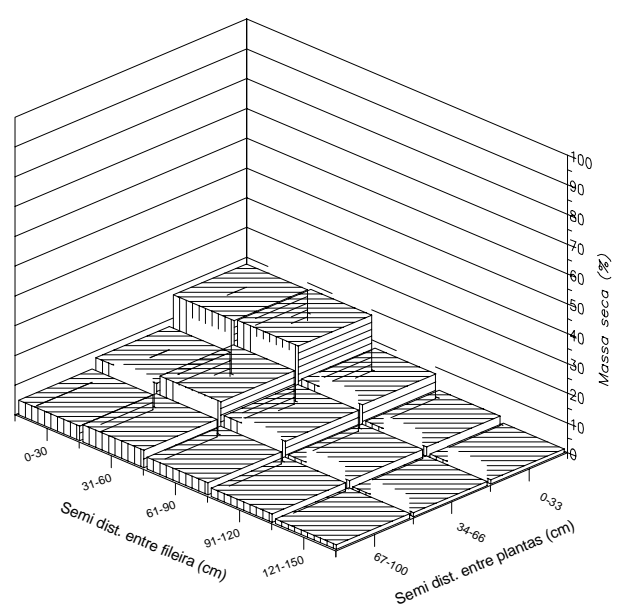

a

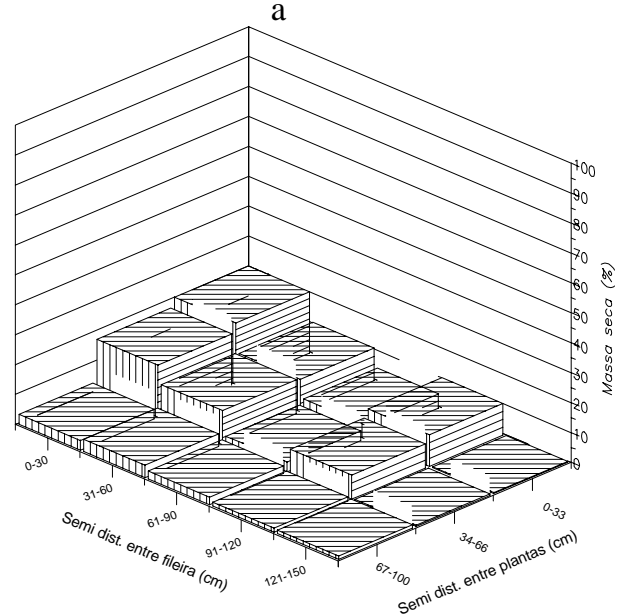

$\mathrm{c}$
Para determinação da distribuição do sistema radicular da videira em cada sistema de irrigação, abriu-se uma trincheira entre duas plantas consecutivas, paralela à fileira de plantas, até a profundidade de $120 \mathrm{~cm}$, de modo a permitir a visualização da metade do sistema radicular de cada videira. Em cada trincheira foram analisados cinco perfis, situados a 150, 120, 90, 60, e $30 \mathrm{~cm}$ de distância em relação à fileira de plantas. Cada perfil foi dividido em 24 monolitos de dimensões de $3 \mathrm{~cm}$ x $30 \mathrm{~cm}$ x $30 \mathrm{~cm}$, coletados separadamente.

No laboratório, as raízes foram separadas do solo, lavadas e agrupadas manualmente, utilizando-se uma régua milimetrada, em quatro intervalos de diâmetro de raízes: menor que $2 \mathrm{~mm}$, de 2 a $5 \mathrm{~mm}$, de 5 a $10 \mathrm{~mm}$ e maior que $10 \mathrm{~mm}$; após a secagem, em estufa a $60^{\circ} \mathrm{C}$ até peso constante, determinou-se a massa seca das raízes

\section{RESULTADOS E DISCUSSÃO}

Nas Tabelas 2 e 3 pode-se observar a distribuição horizontal do sistema radicular da videira, em base de massa seca de raízes, sob irrigação por microaspersão e por gotejamento.

Analisando-se a distribuição horizontal do sistema radicular da videira, constatou-se que mais de 90 e de $86 \%$ da massa seca das raízes de absorção de água e nutrientes (raízes com diâmetros inferiores a $10 \mathrm{~mm}$ ) estão concentradas a $90 \mathrm{~cm}$ de distância em relação à fileira de plantas, correspondentes aos sistemas de irrigação por gotejamento e microaspersão, respectivamente (Tabelas 2 e 3 e Figura 1a, b, c, d) porém quando

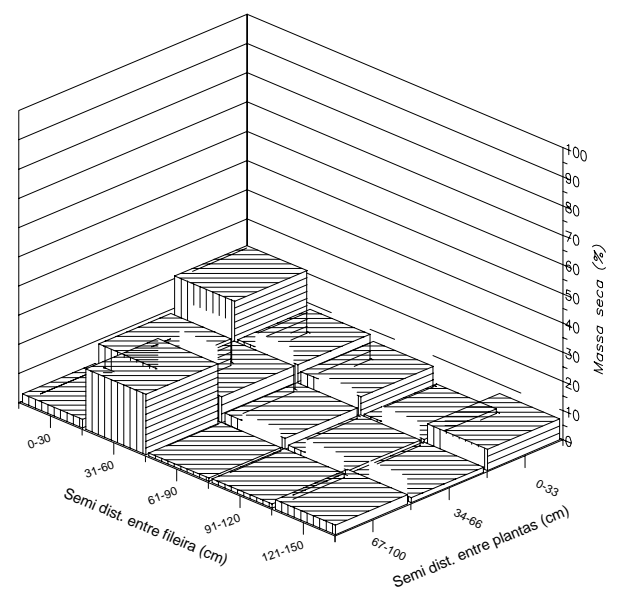

$\mathrm{b}$

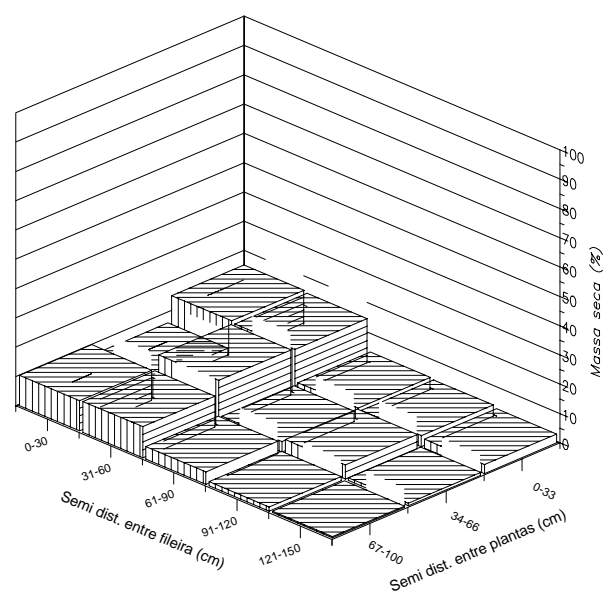

a

Figura 1- Distribuição horizontal das raízes, de absorção de água e nutrientes, da videira sob irrigação por gotejamento na camada 0 a 30 (a) e 30 a $60 \mathrm{~cm}$ (b) e por microaspersão, na camada 0 a 30 (c) e 30 a $60 \mathrm{~cm}$ (d), em vertissolo 
se analisa, de maneira detalhada, a distribuição dessas raízes na camada superficial do solo, pode-se observar que as raízes com diâmetro inferior a $2 \mathrm{~mm}$ e as com diâmetro entre 5 e $10 \mathrm{~mm}$, apresentam-se mais concentradas em relação à fileira de plantas, sob irrigação por gotejamento, quando comparadas com o sistema de irrigação por microaspersão, com exceção das raízes com diâmetro entre 2 e $5 \mathrm{~mm}$. Quando se consideram as raízes de sustentação (raízes com diâmetro maior que $10 \mathrm{~mm}$ ) verificase que elas estão ainda mais concentradas $(87,53 \%)$ em relação à fileira de plantas, sob irrigação por gotejamento que sob irrigação por microaspersão $(65,58 \%)$ conforme Tabelas 2 e 3 , respectivamente. Resultados similares foram encontrados por Van Zyl (1988).

Apesar da elevada infiltração lateral, característica dos Vertissolos, e de beneficiar o aumento da área transversal do bulbo molhado sob irrigação por gotejamento, a irrigação por microaspersão proporcionou melhor uniformidade de distribuição horizontal do sistema radicular da videira (Figura 1a, b, c, d).

Tabela 2. Distribuição do sistema radicular da videira nos sentidos horizontal à fileira de plantas e vertical, em Vertissolo, sob irrigação por gotejamento

\begin{tabular}{|c|c|c|c|c|c|c|c|c|c|c|c|c|c|c|}
\hline \multirow{4}{*}{$\begin{array}{c}\varnothing \text { das } \\
\text { Raizes } \\
(\mathrm{mm})\end{array}$} & \multirow{4}{*}{$\begin{array}{c}\text { Camada } \\
(\mathrm{cm})\end{array}$} & \multicolumn{13}{|c|}{ Semi-distância entre fileiras $(\mathrm{cm})$} \\
\hline & & \multicolumn{2}{|c|}{$0-30$} & \multicolumn{2}{|c|}{$30-60$} & \multicolumn{2}{|c|}{$60-90$} & \multicolumn{2}{|c|}{$90-120$} & \multicolumn{2}{|c|}{$120-150$} & \multicolumn{2}{|c|}{ Total } & \multirow{2}{*}{$\begin{array}{l}\text { Média } \\
\text { cumulada }\end{array}$} \\
\hline & & Peso & & Peso & & Peso & & Peso & & Peso & & Peso & & \\
\hline & & (g) & $(\%)$ & (g) & $(\%)$ & $(\mathrm{g})$ & $(\%)$ & (g) & $(\%)$ & (g) & $(\%)$ & $(\mathrm{g})$ & $(\%)$ & $(\%)$ \\
\hline \multirow[t]{6}{*}{$<2$} & $0-30$ & 160,0 & 51,6 & 89,1 & 28,7 & 33,3 & 10,7 & 15,9 & 5,1 & 11,9 & 3,8 & 310,2 & 84,7 & 84,7 \\
\hline & $30-60$ & 9,0 & 21,0 & 20,4 & 47,6 & 4,1 & 9,6 & 2,8 & 6,5 & 6,6 & 15,4 & 42,9 & 11,7 & 96,4 \\
\hline & $60-90$ & 6,5 & 52,4 & 1,5 & 12,1 & 0,8 & 6,5 & 2,3 & 18,5 & 1,3 & 10,5 & 12,4 & 3,4 & 99,8 \\
\hline & $90-120$ & 0,2 & 25,0 & 0,1 & 12,5 & 0,0 & 0,0 & 0,1 & 12,5 & 0,4 & 50,0 & 0,8 & 0,2 & 100 \\
\hline & Total & 175,7 & 48,0 & 111,1 & 30,3 & 38,2 & 10,4 & 21,1 & 5,8 & 20,2 & 5,5 & 366,3 & & \\
\hline & Acum & & 48,0 & & 78,3 & & 88,7 & & 94,5 & & 100 & & & \\
\hline \multirow[t]{6}{*}{2 a 5} & $0-30$ & 99,9 & 42,0 & 77,3 & 32,5 & 37,8 & 15,9 & 18,7 & 7,9 & 4,1 & 1,7 & 237,8 & 88,9 & 88,9 \\
\hline & $30-60$ & 9,9 & 45,0 & 4,5 & 20,5 & 3,6 & 16,4 & 0,8 & 3,6 & 3,2 & 14,5 & 22,0 & 8,2 & 97,1 \\
\hline & $60-90$ & 4,3 & 57,3 & 1,9 & 25,3 & 0,7 & 9,3 & 0,1 & 1,3 & 0,5 & 6,7 & 7,5 & 2,8 & 99,9 \\
\hline & $90-120$ & 0,0 & 0,0 & 0,0 & 0,00 & 0,0 & 0,0 & 0,2 & 100 & 0,0 & 0,0 & 0,2 & 0,1 & 100 \\
\hline & Total & 114,1 & 42,6 & 83,7 & 31,3 & 42,2 & 15,7 & 19,8 & 7,4 & 7,8 & 2,9 & 267,5 & 100 & \\
\hline & Acum & & 42,7 & & 73,9 & & 89,7 & & 97,1 & & 100 & & & \\
\hline \multirow[t]{6}{*}{5 a 10} & $0-30$ & 65,5 & 53,8 & 40,7 & 33,4 & 12,2 & 10,0 & 3,3 & 2,7 & 0,0 & 0,0 & 121,7 & 85,9 & 85,9 \\
\hline & $30-60$ & 8,6 & 49,1 & 6,6 & 37,7 & 1,9 & 10,9 & 0,2 & 1,1 & 0,2 & 1,1 & 17,5 & 12,3 & 98,2 \\
\hline & $60-90$ & 0,9 & 36,0 & 1,6 & 64,0 & 0,0 & 0,0 & 0,0 & 0,0 & 0,0 & 0,0 & 2,5 & 1,8 & 100 \\
\hline & $90-120$ & 0,0 & 0,0 & 0,0 & 0,0 & 0,0 & 0,0 & 0,0 & 0,0 & 0,0 & 0,0 & 0,0 & 0,0 & 100 \\
\hline & Total & 75,0 & 52,9 & 48,9 & 34,5 & 14,1 & 10,0 & 3,5 & 2,5 & 0,2 & 0,1 & 141,7 & 100 & \\
\hline & Acum & & 52,9 & & 87,5 & & 97,4 & & 99,9 & & 100 & & & \\
\hline \multirow[t]{6}{*}{$<10$} & $0-30$ & 325,4 & 48,6 & 207,1 & 30,9 & 83,3 & 12,4 & 38,0 & 5,7 & 16,0 & 2,4 & 669,8 & 86,4 & 86,4 \\
\hline & $30-60$ & 27,6 & 33,5 & 31,5 & 38,2 & 9,6 & 11,6 & 3,8 & 4,6 & 10,0 & 12,1 & 82,5 & 10,6 & 97,0 \\
\hline & $60-90$ & 11,6 & 52,0 & 5,0 & 22,4 & 1,5 & 6,7 & 2,4 & 10,7 & 1,8 & 8,1 & 22,3 & 2,9 & 99,9 \\
\hline & $90-120$ & 0,2 & 25,0 & 0,1 & 12,5 & 0,0 & 0,0 & 0,4 & 50,0 & 0,1 & 12,5 & 0,8 & 0,1 & 100 \\
\hline & Total & 364,8 & 47,0 & 243,7 & 31,4 & 94,5 & 12,2 & 44,5 & 5,8 & 27,9 & 3,6 & 775,4 & 100 & \\
\hline & Acum & & 47,0 & & 78,5 & & 90,6 & & 96,4 & & 100 & & & \\
\hline \multirow[t]{6}{*}{.$>10$} & $0-30$ & 202,1 & 87,1 & 28,6 & 12,3 & 0,0 & 0,0 & 1,4 & 0,6 & 0,0 & 0,0 & 232,1 & 96,7 & 96,7 \\
\hline & $30-60$ & 8,0 & 100 & 0,0 & 0,0 & 0,0 & 0,0 & 0,0 & 0,0 & 0,0 & 0,0 & 8,0 & 3,3 & 100 \\
\hline & $60-90$ & 0,0 & 0,0 & 0,0 & 0,0 & 0,0 & 0,0 & 0,0 & 0,0 & 0,0 & 0,0 & 0,0 & 0,0 & 100 \\
\hline & $90-120$ & 0,0 & 0,0 & 0,0 & 0,0 & 0,0 & 0,0 & 0,0 & 0,0 & 0,0 & 0,0 & 0,0 & 0,0 & 100 \\
\hline & Total & 210,1 & 87,5 & 28,6 & 11,9 & 0,0 & 0,0 & 1,4 & 0,6 & 0,0 & 0,0 & 240,1 & 100 & \\
\hline & Acum & & 87,5 & & 99,4 & & 99,4 & & 100 & & 100 & & & \\
\hline
\end{tabular}


Tabela 3. Distribuição do sistema radicular da videira nos sentidos horizontal à fileira de plantas e vertical, em Vertissolo, sob irrigação por microaspersão

\begin{tabular}{|c|c|c|c|c|c|c|c|c|c|c|c|c|c|c|}
\hline \multirow{4}{*}{$\begin{array}{l}\varnothing \text { das } \\
\text { raizes } \\
(\mathrm{mm})\end{array}$} & \multirow{4}{*}{$\begin{array}{c}\text { Camada } \\
(\mathrm{cm})\end{array}$} & \multicolumn{13}{|c|}{ Semi distância entre fileiras $(\mathrm{cm})$} \\
\hline & & \multicolumn{2}{|c|}{$0-30$} & \multicolumn{2}{|c|}{$30-60$} & \multicolumn{2}{|c|}{$60-90$} & \multicolumn{2}{|c|}{$90-120$} & \multicolumn{2}{|c|}{$120-150$} & \multicolumn{2}{|c|}{ Total } & Média \\
\hline & & Peso & & Peso & & Peso & & Peso & & Peso & & Peso & & umulada \\
\hline & & $(\mathrm{g})$ & $(\%)$ & (g) & $(\%)$ & (g) & $(\%)$ & (g) & $(\%)$ & $(\mathrm{g})$ & $(\%)$ & (g) & $(\%)$ & $(\%)$ \\
\hline \multirow[t]{6}{*}{$<2$} & $0-30$ & 101,8 & 26,4 & 136,0 & 35,3 & 83,2 & 21,6 & 39,6 & 10,3 & 25,0 & 6,5 & 385,6 & 84,5 & 84,5 \\
\hline & $30-60$ & 24,4 & 39,0 & 26,0 & 41,6 & 7,3 & 11,7 & 2,6 & 4,2 & 2,2 & 3,5 & 62,5 & 13,7 & 98,2 \\
\hline & $60-90$ & 3,3 & 43,4 & 2,4 & 31,6 & 0,8 & 10,5 & 0,4 & 5,3 & 0,7 & 9,2 & 7,6 & 1,7 & 99.8 \\
\hline & $90-120$ & 0,3 & 42,9 & 0,1 & 14,3 & 0,1 & 14,3 & 0,1 & 14,3 & 0,1 & 14,3 & 0,7 & 0,2 & 100 \\
\hline & Total & 129,8 & 28,4 & 164,5 & 36,0 & 91,4 & 20,0 & 42,7 & 9,4 & 28,0 & 6,1 & 456,4 & & - \\
\hline & Acum & & 28,4 & & 64,5 & & 84,5 & & 93,9 & & 100 & & & \\
\hline \multirow[t]{6}{*}{2 a 5} & $0-30$ & 94,2 & 30,9 & 97,7 & 32,0 & 67,5 & 22,1 & 31,4 & 10,3 & 14,1 & 4,6 & 304,9 & 91,3 & 91,3 \\
\hline & $30-60$ & 7,1 & 26,4 & 11,4 & 42,4 & 4,6 & 17,1 & 3,3 & 12,3 & 0,5 & 1,9 & 27,0 & 8,1 & 99,4 \\
\hline & $60-90$ & 0,6 & 30,0 & 0,3 & 15,0 & 0,2 & 10,0 & 0,5 & 25,0 & 0,4 & 20,0 & 2,0 & 0,6 & 100 \\
\hline & $90-120$ & 0,0 & 0,0 & 0,0 & 0,0 & 0 & 0 & 0 & 0 & 0 & 0 & 0 & 0 & 100 \\
\hline & Total & 101,9 & 30,5 & 109,4 & 32,8 & 72,3 & 21,7 & 35,2 & 10,5 & 15,0 & 4,5 & 333,8 & & \\
\hline & Acum & & 30,5 & & 63,3 & & 85,0 & & 95,5 & & 100 & & & \\
\hline \multirow[t]{6}{*}{5 a 10} & $0-30$ & 100,3 & 39,9 & 104,4 & 41,5 & 31,7 & 12,6 & 13,8 & 5,5 & 1,4 & 0,6 & 251,6 & 95,3 & 95,3 \\
\hline & $30-60$ & 1,8 & 14,5 & 4,3 & 34,7 & 0,3 & 2,4 & 4,3 & 34,7 & 1,7 & 13,7 & 12,4 & 4,7 & 100 \\
\hline & $60-90$ & 0,0 & 0,0 & 0,0 & 0,0 & 0,0 & 0,0 & 0,0 & 0,0 & 0,0 & 0,0 & 0,0 & 0,0 & 100 \\
\hline & $90-120$ & 0,0 & 0,0 & 0,0 & 0,0 & 0,0 & 0,0 & 0,0 & 0,0 & 0,0 & 0,0 & 0,0 & 0,0 & 100 \\
\hline & Total & 102,1 & 38,7 & 108,7 & 41,2 & 32,0 & 12,1 & 18,1 & 6,9 & 3,1 & 1,2 & 264,0 & & \\
\hline & Acum & & 38,7 & & 79,8 & & 92,0 & & 98,8 & & 100 & & & \\
\hline \multirow[t]{6}{*}{$<10$} & $0-30$ & 296,4 & 31,5 & 338,1 & 35,9 & 182,4 & 19,4 & 84,9 & 9,0 & 40,5 & 4,3 & 942,3 & 89,4 & 89,4 \\
\hline & $30-60$ & 33,3 & 32,7 & 41,7 & 40,9 & 12,2 & 12,0 & 10,2 & 10,0 & 4,5 & 4,4 & 101,9 & 9,7 & 99,0 \\
\hline & $60-90$ & 3,9 & 41,1 & 2,6 & 27,4 & 1,0 & 10,5 & 1,0 & 10,5 & 1,0 & 10,5 & 9,5 & 0,9 & 99,9 \\
\hline & $90-120$ & 0,3 & 42,7 & 0,1 & 14,3 & 0,1 & 14,3 & 0,1 & 14,3 & 0,1 & 14,3 & 0,7 & 0,1 & 100 \\
\hline & Total & 333,9 & 31,7 & 382,5 & 36,3 & 195,7 & 18,6 & 96,2 & 9,1 & 46,1 & 4,4 & 054,4 & 100 & \\
\hline & Acum & & 31,7 & & 67,9 & & 86,5 & & 95,6 & & 100 & & & \\
\hline \multirow[t]{6}{*}{.$>10$} & $0-30$ & 188,4 & 65,6 & 55,3 & 19,3 & 16,4 & 5,7 & 17,7 & 6,2 & 9,5 & 3,3 & 287,3 & 100 & 100 \\
\hline & $30-60$ & 0,0 & 0,0 & 0,0 & 0,0 & 0,0 & 0,0 & 0,0 & 0,0 & 0,0 & 0,0 & 0,0 & 0,0 & 100 \\
\hline & $60-90$ & 0,0 & 0,0 & 0,0 & 0,0 & 0,0 & 0,0 & 0,0 & 0,0 & 0,0 & 0,0 & 0,0 & 0,0 & 100 \\
\hline & $90-120$ & 0,0 & 0,0 & 0,0 & 0,0 & 0,0 & 0,0 & 0,0 & 0,0 & 0,0 & 0,0 & 0,0 & 0,0 & 100 \\
\hline & Total & 188,4 & 65,6 & 55,3 & 19,3 & 16,4 & 5,7 & 17,7 & 6,2 & 9,5 & 3,3 & 287,3 & 100 & \\
\hline & Acum & & 65,6 & & 84,8 & & 90,5 & & 96,7 & & 100 & & & \\
\hline
\end{tabular}

Isto pode estar condicionado a uma melhor uniformidade de distribuição de nutrientes nitrogenados e potássicos, aplicados via água de irrigação.

Analisando-se a distribuição vertical das raízes de videira, verificou-se que mais de $84 \%$ da massa seca das raízes de absorção de água e nutrientes estavam concentrados na camada de 0 - 30cm e mais de $96 \%$ na camada de $0-60 \mathrm{~m}$ de profundidade, para ambos os sistemas de irrigação. Constatou-se, também, que mais de $96 \%$ das raízes de sustentação ( $\varnothing>10 \mathrm{~mm})$ estavam concentradas na camada de 0 - 30cm de profundidade; apenas 3,50 e $1,80 \%$ das raízes com diâmetro inferior a $2 \mathrm{~mm}$, foram encontrados nas camadas de $60-120 \mathrm{~cm}$ de profundidade, sob os sistemas de irrigação por gotejamento e por microaspersão, respectivamente (Tabelas 2 e 3 ).

A pequena penetração de raízes a partir de $30 \mathrm{~cm}$ de profundidade poderá estar sendo restringida devido à ocorrência de uma microporosidade muito intensa, o que dificulta a penetração de água e, consequentemente, a reposição do nível 
adequado de oxigênio nessas camadas do solo, conforme Segiun (1972) e Taylor (1949) ambos citados por Richards (1983) e Sides \& Barden (1970) citados por Miller et al. (1975) e que solos com textura moderadamente argilosa podem favorecer a concentração das raízes nas primeiras camadas do solo (Nagarajah, 1987).

Aragão (1977) estudando níveis de manejo de água na cultura da cana-de-açúcar em Vertissolo, constatou que o armazenamento e o esgotamento da água no solo se dispõem numa forma triangular, de modo que um dos vértices do triângulo se situa na profundidade de $100 \mathrm{~cm}$, onde as tensões de umidade permanecem praticamente constantes, ligeiramente superiores a 2 atm

Vahallyay (s.d:) constatou que a baixa condutividade hidráulica do solo saturado, é devida à alta taxa de dispersão e de hidratação do solo refletindo, assim, uma especial redistribuição do tamanho dos poros. Em decorrência disto, uma quantidade considerável de água é fortemente retida nos microporos, adquirindo um estado especial semi-sólido, o que pode tornar a condutividade hidráulica desprezível.

Em decorrência dos resultados obtidos, sugere-se a realização de estudos concernentes ao manejo de solo e água, de modo a proporcionar maior volume de solo explorado pelo sistema radicular da videira em Vertissolo.

\section{CONCLUSÕES}

1. Constatou-se que mais de 86 e de $90 \%$ da massa seca das raízes de absorção de água e nutrientes (raízes com diâmetros inferiores a $10 \mathrm{~mm}$ ) estava concentrada a $90 \mathrm{~cm}$ de distância em relação à fileira de plantas, correspondentes aos sistemas de irrigação por gotejamento e por microaspersão, respectivamente.

2. Verificou-se que as raízes de sustentação apresentaramse mais concentradas $(87,10 \%)$ em relação à fileira de plantas, sob irrigação por gotejamento, que sob irrigação por microaspersão (65,58\%).

3. Verificou-se que mais de $84 \%$ da massa seca das raízes de absorção de água e nutrientes estava concentrada na camada de $0-30 \mathrm{~cm}$ e mais de $96 \%$ na camada de $0-60 \mathrm{~cm}$ de profu ndidade, para ambos os sistemas de irrigação.
4. Constatou-se, também, que mais de $96 \%$ das raízes de sustentação $(\varnothing>10 \mathrm{~mm})$ estavam concentradas na camada de 0-30cm de profundidade; apenas 3,50 e 1,80\% das raízes com diâmetros inferiores a $2 \mathrm{~mm}$, foram encontradas nas camadas de $60-120 \mathrm{~cm}$ de profundidade, sob os sistemas de irrigação por gotejamento e por microaspersão, respectivamente.

\section{REFERÊNCIAS BIBLIOGRÁFICAS}

ARAGÃO, O.P. Evapotranspiração da cana-de-açúcar no submédio São Francisco. In: SEMINÁRIO NACIONAL DE IRRIGAÇÃO E DRENAGEM, 3, 1975, Fortaleza. Anais...Fortaleza: DNOCS/ABID, 1977. v. 3, p. 85-91.

ARAÚJO, F.J.; WILLIAMS, L.E. Dry matter and nitrogen partitioning and root growth of young field-grown. Thompson seedless grapevines. Vitis, Suebeldingen, v. 27, n. 1, p. 21-32, 1988.

EMBRAPA. Serviço Nacional de Levantamento e Conservação de Solos. (Rio de Janeiro, RJ) Manual de métodos de análise de solo. Rio de Janeiro, 1979.

KLIEWER, W.M. Grapevines physiology: how does a grapevine make sugar? Davis: University of California, 1981, 13p. il. (University of California. Leaflet, 21231).

MILLER, R.W.; UNHANAND, K.; PETERSON, H.B. Water management of heavy soils: a "State-of-the-Art" Paper. 1975. 163p.

MORLAT, R.; JACQUET, A. The soil effects on the grapevine root system in several vineyards of the Loire valley (France). Vitis, Suebeldingen, v. 32, n. 1, p. 35-42, 1993.

NAGARAJAH, S. Effects of soil texture on the rooting patterns of Thompson. Seedles wines on own roots and on Ramsey rootstock in irrigated vineyards. American Journal of Enology and Viticulture, Davis, v.38, n.1, p.54-59, 1987.

RICHARDS, D. The grape root system. Hortcultural Review, Victoria, Austrália. v. 5, p. 127-168, 1983.

SCHUURMAN, J.J.; GOEDEWAAGEN, M.A.J. Methods for the examination of root systems and roots. Wageningen: Centre for Agricultural Publications and Documentation, 1965. 85p.

VAN ZYL, J.L. The grapevine root and is environment. Pretoria: Departament of Agriculture and Water Supply, 1988. (Technical communication, 215). 